\title{
Predictive Models for the Ultimate Tensile and Yield Stresses Occurring in Joints of Untreated Friction Stir Welded 2017AA (ENAW-AlCu4MgSi) Plates
}

\author{
Mohamed-Ali Rezgui ${ }^{1}$, Ali-Chedli Trabelsi ${ }^{2}$, Hassen Bouzaiene ${ }^{2}$, Mahfoudh Ayadi $^{3}$ \\ ${ }^{1}$ Department of Mechanical Engineering, Taibah University, College of Engineering, Yanbu, Saudi Arabia \\ ${ }^{2}$ UR-MSSDT (99-UR11-46), Tunis National Higher School of Engineering, University of Tunis, ENSIT, Tunisia \\ ${ }^{3}$ Department of Mechanical Engineering, University of Carthage, National Engineering School of Bizerte ENIB, Bizerte, Tunisia \\ Email:mohamedali.rezgui@gmail.com, ali.trbls@gmail.com, bouzaiene.hassen@gmail.com,mahfoudh.ayadi@esstt.rnu.tn
}

Received April 26, 2013; revised May 27, 2013; accepted June 3, 2013

Copyright (C) 2013 Mohamed-Ali Rezgui et al. This is an open access article distributed under the Creative Commons Attribution License, which permits unrestricted use, distribution, and reproduction in any medium, provided the original work is properly cited.

\begin{abstract}
Friction Stir Welding (FSW) processes have been applied in numerous industrial fields and broadly embraced by the research community. In this paper, given three FSW process parameters, namely, the tool rotation speed N (rpm), the tool traverse feed $\mathrm{F}(\mathrm{mm} / \mathrm{min})$ and the tool pin/shoulder diameters ratio $(\mathrm{r} \%)$, we purpose to ascertain their impact on joints Ultimate Tensile Stress (UTS) and joints Yield Stress (YS). The FSW has been executed using $6 \mathrm{~mm}$ thick rolled plate in 2017AA. For the design of experiments strategy, we conducted a face centered central composite strategy through which 18 trials have been executed. Then, we utilized the RSM technique to formulate the predictive models which are relevant to the (UTS) and (YS) outputs. Accordingly, the study has pointed out the prevalence of the tool rotation speed and the tool diameters ratio factors; however, the tool traverse feed (F) was found trivial and statistically insignificant. Likewise, the sensitivity analysis regarding factors N, F and $\mathrm{r} \%$ on both (UTS) and (YS) has exhibited the dominance of the tool diameters ratio $(\mathrm{r} \%)$, indistinctively.
\end{abstract}

Keywords: Friction Stir Welding; Response Surface Methodology; ANOVA; Sensitivity Analysis; Yield Stress; Ultimate Tensile Stress; 2017AA

\section{Introduction}

The Friction Stir Welding (FSW) is a derivative of the conventional friction welding process that is traced back to the early 1960s. The process was patented at the TWI in 1991 [1] and has been applied heavily in many Industrial fields. Many research works have shown the superiority of the FSW on conventional fusion welding. And, the process has concerned polymers [2] and ferrous and non ferrous alloys. Furthermore, the FSW has coped with similar, dissimilar [3] and metal matrix composites [4].

In FSW, a rotating tool with a central pin is driven in the interface of two plates/sheets to be welded. The tool is then fed in the joint line prior retracting to a rest/reference position. The material softens by means of the heat which is generated by the tool/part friction movement and the pin malaxation effect. Because the heat is mainly produced under the tool's shoulder, a local plastic deformation zone occurred so that the welded interface is stirred and homogenously formed. Finally, the tool is pulled away and the weldment converts into a solid state during the cooling phase [5].

During the FSW process, the material stirring power, the non-isothermal treatment and the material flow determine, at a large extent, the mechanical and metal properties of the joint weld zones (i.e., the weld nugget, the thermo-mechanical affected zone and the heat affected zone). The joint macrostructure, the residual stress and the fracture surface tests are important qualitative properties which are inspected in FSW joints. But also, other quantitative properties are required to control the joints quality such that the yield stress (YS) and the Ultimate Tensile Stress (UTS) [6,7]. In numerous works, both the quantitative and qualitative properties of FSW joints have been correlated with the process parameters, for instance, the rotation speed and welding feed rate $[8,9]$, the tool axial load $[10,11]$, the tool geometry $[12,13]$ and the weld interface orientation [14]. One challenge; however, is how FSW parameters could be determined so that high 
quality joints are produced cost-effectively. Statistical techniques, among other solutions, have brought substantial contribution in this regard. The statistical techniques may be viewed as four main classes, 1) factorial design and analysis of variance (ANOVA) $[15,16], 2)$ response surface method RSM [17-19], 3) Taguchi method [20,21], and 4) artificial neural network \& Genetic method [22, 23].

For the FSW in the 2017AA (ENAW-AlCu4MgSi), a few studies have been carried out $[24,25]$. This study has considered such an alloy. In a recent work [26], we have coped with the two process responses joints Tensile Elongation (E\%) and joints Hardening Capacity $(\mathrm{Hc})$, and at present, we shall report on the two quantitative properties (UTS, YS). Table 1 enlists the nominal mechanical characteristics of the aluminum 2017 AA.

The remaining text is structured as follows. Section 2 lies out the study framework, the design of experiments (DoE) strategy as well as the true stress-strain curves of the tested coupons as benchmarked against the BM. Section 3 discusses and lies out the ANOVA(s) and RSM models being fit to the process responses (UTS) and (YS). Finally, Section 4 will cope with the sensitivity analysis study of the operating factors $\mathrm{N}, \mathrm{F}$ and $\mathrm{r} \%$.

\section{Experimental}

\subsection{Experiment Setup}

The experiment FSW runs have been executed on a 7.5 $\mathrm{kw}$ powered universal mill (Momac model), rating up to $1700 \mathrm{r} / \mathrm{min}$ in rotation speed and up to $1080 \mathrm{~mm} / \mathrm{min}$ in tool feed. A series of $6 \mathrm{~mm}$ thick plates in 2017AA were cut into $(250 \times 90) \mathrm{mm}$ rectangular shapes. And, for each run, a pair of plates (set) disposed in butt configuration are welded along their length edge. The welding tool is manufactured in a high steel alloy (35 Rockwell-C Hardness). Figure 1 displayed the experiment setting as well as the tool geometry.

\subsection{Design of Experiment Strategy}

The variation assessment and response predictive models regarding (UTS) and (YS) are assessed using the RSM

Table 1. Mechanical properties of the 2017AA (BM).

\begin{tabular}{cccc}
\hline $\begin{array}{c}\text { Base Metal } \\
\text { 2017AA }\end{array}$ & UTS/(MPa) & YS/(MPa) & E/(\%) \\
\hline $\begin{array}{c}\text { Mechanical } \\
\text { properties }\end{array}$ & 427 & 276 & 22 \\
$\begin{array}{c}\text { Chemical } \\
\text { Composition } \\
(\%)\end{array}$ & $\mathrm{Fe}<0.7427$ & Si. $0.2-0.8$ & Mn. $0.4-1.0$ \\
\hline & $\mathrm{Zn}<0.25$ & $\mathrm{Cu} .3 .5-5.5$ & Mg. $0.4-1.0$ \\
\hline
\end{tabular}

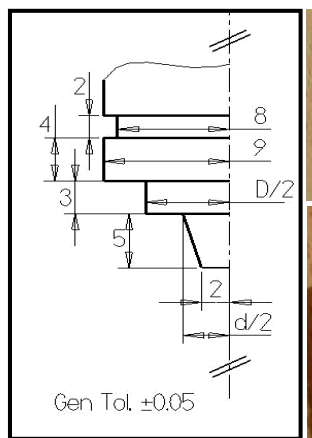

(a)

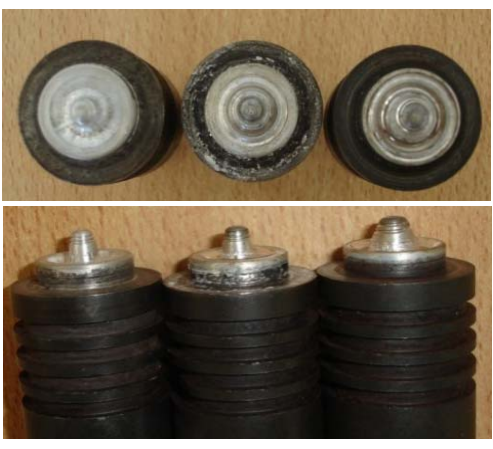

(b)
Figure 1. (a) Shoulder/pin geometry; (b) Tools photography.

technique. The experiment has been undertaken in a sequential strategy. First, a $2^{3}$ plan is put forward to fit first-order models for (UTS) and (YS). Then, owing to the model Lack of Fit (LoF), we augmented the design with six axial runs and four center points to fit higher order models, thereby, a face-centered composite design (FCCD) $(\alpha= \pm 1)$ was considered.

For the levels setting of N, F and $\mathrm{r} \%$, we performed some preliminary trials to better assign lower, intermediate and higher levels of factors. Mainly, we took into account the macroscopic observation of joints texture and the surface defects (e.g., surface irregularities, excessive flash, lack of penetration, surface-open tunnels, etc.). Accordingly, for the DoE coding, the actual units of the -1 and +1 levels are set at $653 \mathrm{rpm}$ and $1280 \mathrm{rpm}$ for the rotation speed $(\mathrm{N}), 67 \mathrm{~mm} / \mathrm{min}$ and $109 \mathrm{~mm} / \mathrm{min}$ for the tool traverse feed and, $33 \%$ and $44 \%$ for the tool diameters ratio $(\mathrm{r} \%)$. The intermediate setting of $\mathrm{N}, \mathrm{F}$ and $\mathrm{r} \%$ has been maintained at $910 \mathrm{rpm}, 86 \mathrm{~mm} / \mathrm{min}$ and $39 \%$, respectively (Table 2). Table 3 depicts the maintained constant factors throughout the experiment time.

So far, the design encoding, ANOVA tables and sensitivity analysis will be assisted by Minitab ${ }^{\circledR}$ software. Table 4 shows the study DoE layout as expressed in natural coding units.

\subsection{Specimens True Stress-Strain}

The tensile specimens (ASME E8M-04) have been cut longitudinally in the butt FSWed plates as shown in Figure 2. Figure 3 is a photography of the tensile specimens after fracture. Insofar, these are split into 8 factorial runs, $\mathrm{F}_{\mathrm{i}=1,8}$ (Figure 3(a)), 4 center point runs, $\mathrm{C}_{\mathrm{i}=1.4}$ (Figure 3(b)) and 6 axial runs, $A_{i=1.6}$ (Figure 3(c)). Each specimen has been undergone a tensile test at room temperature and at a crosshead speed of $0.1 \mathrm{~mm} / \mathrm{min}$. Among the 18 runs, nine of the tension loaded specimens have failed midway of the gauge length and six failed in the vicinity of the grip region. After specimens have been undergone tensile tests, true-stress curves generated for each, have similar pattern compared with the BM plot. 


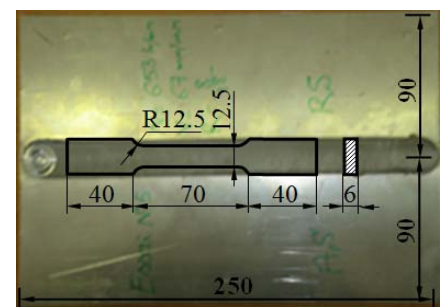

Figure 2. Tensile test specimens (ASME E8M-04).

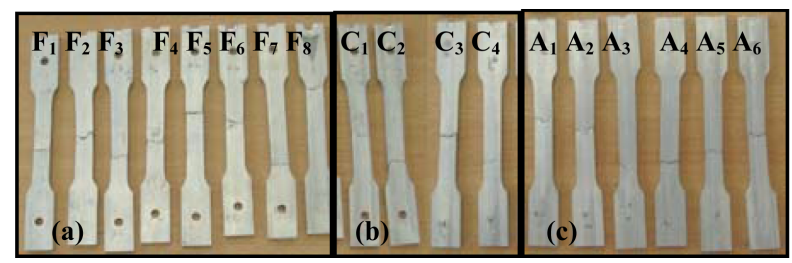

Figure 3. Specimens and zones of fracture after tensile tests.

Table 2. Factors setting levels for the FCCD.

\begin{tabular}{cccc}
\hline \multirow{2}{*}{ Factor } & \multicolumn{3}{c}{ Levels setting } \\
\cline { 2 - 4 } & $\mathbf{( - 1 )}$ & $\mathbf{( 0 )}$ & $\mathbf{( + 1 )}$ \\
\hline $\mathrm{N} /(\mathrm{rpm})$ & 653 & 910 & 1280 \\
$\mathrm{~F} /(\mathrm{mm} / \mathrm{min})$ & 67 & 86 & 109 \\
$\mathrm{r} \%$ & 33 & 39 & 44 \\
\hline
\end{tabular}

Table 3. Held-constant factors.

\begin{tabular}{cc}
\hline Parameters & Value \\
\hline Pin height $/(\mathrm{mm})$ & 5.3 \\
Shoulder diameter $/(\mathrm{mm})$ & 18 \\
Pin small cone diameter $/(\mathrm{mm})$ & 4 \\
Tool inclination $/\left({ }^{\circ}\right)$ & 3 \\
Infeed $/(\mathrm{mm})$ & 0.94 \\
\hline
\end{tabular}

\section{RSM for the Empirical Models of UTS and YS}

\subsection{Empirical Model for the Ultimate Tensile Stress (UTS)}

In this section, we shall lie out the descriptive model which can convey variation in the (UTS) response, reliably. Allowing for a threshold of 95\% C.I., the candidate/potential regression model(s) should satisfy the best trade-off among the model statistics, i.e., the LoF, $\mathrm{R}^{2}$, $\mathrm{R}^{2}$-pred, $\mathrm{R}^{2}$-adj and $\mathrm{S}$ (see Table 5).

According to Table 5, it is indicated that both variation in (UTS) and (YS) are satisfactorily described by means of second order models. For (UTS), the variation in factors $\mathrm{N}, \mathrm{F}$ and $\mathrm{r} \%$ explain $93.62 \%$ to $99.48 \%$ of the model variability. However, the variability in (YS) is explained
Table 4. FCCD layout for the FSW process experiment.

\begin{tabular}{|c|c|c|c|c|c|c|c|}
\hline \multicolumn{6}{|c|}{ Factors Setting } & \multirow{2}{*}{\multicolumn{2}{|c|}{$\begin{array}{c}\text { Process } \\
\text { Responses }\end{array}$}} \\
\hline \multicolumn{6}{|c|}{ FCCD } & & \\
\hline Std. & run & Pts. & $\mathrm{N}$ & $\mathrm{F}$ & $\mathrm{r}$ & UTS & YS \\
\hline Ord. & Ord. & Types & $/(\mathrm{rpm})$ & $/(\mathrm{mm} / \mathrm{min})$ & $/(\%)$ & /(MPa) & $/(\mathrm{MPa})$ \\
\hline 17 & 1 & 0 & 910 & 86 & 39 & 202.5 & 42.5 \\
\hline 7 & 2 & 1 & 653 & 109 & 44 & 163.0 & 42.0 \\
\hline 14 & 3 & -1 & 910 & 86 & 44 & 151.0 & 42.0 \\
\hline 9 & 4 & -1 & 653 & 86 & 39 & 232.0 & 51.0 \\
\hline 2 & 5 & 1 & 1280 & 67 & 33 & 165.0 & 50.0 \\
\hline 16 & 6 & 0 & 910 & 86 & 39 & 192.0 & 44.0 \\
\hline 6 & 7 & 1 & 1280 & 67 & 44 & 60.0 & 38.0 \\
\hline 10 & 8 & 1 & 1280 & 86 & 39 & 113.0 & 43.0 \\
\hline 5 & 9 & -1 & 653 & 67 & 44 & 223.0 & 46.0 \\
\hline 11 & 10 & 1 & 910 & 67 & 39 & 202.0 & 48.0 \\
\hline 3 & 11 & -1 & 653 & 109 & 33 & 264.0 & 63.0 \\
\hline 15 & 12 & 1 & 910 & 86 & 39 & 186.0 & 42.0 \\
\hline 4 & 13 & 0 & 1280 & 109 & 33 & 185.0 & 56.0 \\
\hline 13 & 14 & -1 & 910 & 86 & 33 & 244.0 & 59.0 \\
\hline 8 & 15 & 1 & 1280 & 109 & 44 & 62.0 & 36.0 \\
\hline 1 & 16 & 1 & 653 & 67 & 33 & 280.0 & 68.0 \\
\hline 12 & 17 & -1 & 910 & 109 & 39 & 182.0 & 48.0 \\
\hline 18 & 18 & 0 & 910 & 86 & 39 & 204.0 & 43.0 \\
\hline & & oria & )+4 & ter $(0)+$ & vin & Ins $(-1)$ & \\
\hline
\end{tabular}

by $84.48 \%$ to $95.75 \%$ of the variability in N, F and $\mathrm{r} \%$. When screening different models as enlisted Table 5, the LoF and $\mathrm{R}^{2}$ values advise interchangeably more than one candidate model, however, we kept on the highlighted models which exhibit better pure error standard deviation and, above all, higher model predictability $\left(\mathrm{R}^{2}\right.$ (pred)).

Considering the (UTS) full quadratic model shown in Table 5(a), the visual checking of the residual plots regarding the normality, independency, structureless and independence on factor setting does not question the model adequacy. Nevertheless, at $95 \%$ of C.I., the residual distribution is not normal (p-value 0.024) (Figure 4). Also, the ANOVA (see Appendix A) suggests the square terms, $\mathrm{F}^{2}$ and $\mathrm{r} \%{ }^{2}$, as fitted in the regression model are insignificant (p-value 0.750 and 0.825 , resp). Interestingly, the regression $\mathrm{p}$-values of the interactions $(\mathrm{p}=$ $0.000)$ and the squared terms $(p=0.024)$ are found statistically significant at $5 \%$, suggesting presence of curvature in the (UTS) surface contour plot. 


\section{Residual Plots for UTS}
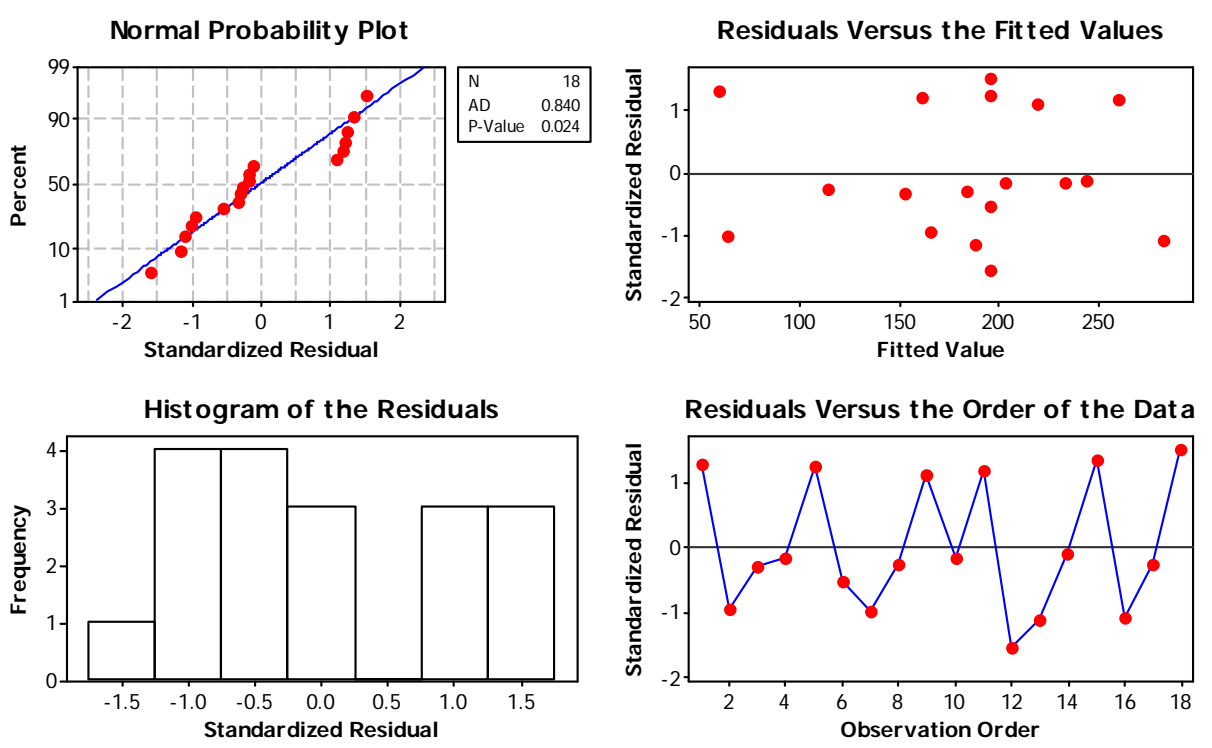

Figure 4. Four-plots for the UTS full quadratic model.

Table 5. RSM models in N, F and $\mathbf{r} \%$. (a) (UTS) response, (b) (YS) response.

\begin{tabular}{|c|c|c|c|c|c|c|c|}
\hline & \multirow{2}{*}{ Model Terms } & \multicolumn{6}{|c|}{ Model Statistics } \\
\hline & & $\mathbf{S}$ & $\mathbf{R}^{2}(\%)$ & $\mathrm{R}^{2}$ (pred) (\%) & $\mathbf{R}^{2}(\operatorname{adj})(\%)$ & PRESS & LoF \\
\hline \multirow{5}{*}{$\begin{array}{c}\text { (a) } \\
\text { UTS model }\end{array}$} & $\mathrm{N}, \mathrm{F}, \mathrm{r} \%$ & 15.39 & 94.59 & 88.41 & 93.44 & 7110.06 & 0.15 \\
\hline & $\mathrm{N}, \mathrm{r} \%$ & 16.16 & 93.62 & 98.72 & 92.77 & 6309.69 & 0.60 \\
\hline & $\mathrm{N}, \mathrm{F}, \mathrm{r} \%, \mathrm{NxF}, \mathrm{Fxr} \%, \mathrm{Nxr} \%$ & 9.42 & 98.41 & 91.51 & 97.54 & 5209.33 & 0.47 \\
\hline & $\mathrm{N}, \mathrm{F}, \mathrm{r} \%, \mathrm{NxF}, \mathrm{Fxr} \%, \mathrm{Nxr} \%, \mathrm{~N}^{2}, \mathrm{~F}^{2}, \mathrm{r}^{2}{ }^{2}$ & 6.30 & 99.48 & 96.12 & 98.90 & 2380.71 & 0.91 \\
\hline & $\mathrm{N}, \mathrm{F}, \mathrm{r} \%, \mathrm{NxF}, \mathrm{Fxr} \%, \mathbf{N x r} \%, \mathrm{~N}^{2}$ & 5.72 & 99.47 & 96.70 & 99.09 & 2026.15 & 0.96 \\
\hline \multirow{5}{*}{$\begin{array}{c}\text { (b) } \\
\text { YS model }\end{array}$} & $\mathrm{N}, \mathrm{F}, \mathrm{r} \%$ & 3.75 & 84.57 & 73.85 & 81.27 & 333.34 & 0.01 \\
\hline & $\mathrm{N}, \mathrm{r} \%$ & 3.63 & 84.48 & 77.64 & 82.41 & 285.09 & 0.12 \\
\hline & $\mathrm{N}, \mathrm{F}, \mathrm{r} \%, \mathrm{NxF}, \mathrm{Fxr} \%, \mathrm{Nxr} \%$ & 3.77 & 87.76 & 44.64 & 81.09 & 705.79 & 0.01 \\
\hline & $\mathrm{N}, \mathrm{F}, \mathrm{r} \%, \mathrm{NxF}, \mathrm{Fxr} \%, \mathrm{Nxr} \%, \mathrm{~N}^{2}, \mathrm{~F}^{2}, \mathrm{r} \%{ }^{2}$ & 2.60 & 95.75 & 65.63 & 90.97 & 438.18 & 0.03 \\
\hline & $\mathrm{N}, \mathbf{r} \%, \mathbf{r} \%^{2}$ & 2.82 & 91.27 & 84.94 & 89.40 & 191.97 & 0.59 \\
\hline
\end{tabular}

Note: candidate sub-sets are highlighted in bolt.

The reduced model of (UTS) as expressed in natural/ active variables is given below:

$$
\begin{aligned}
\overline{\mathrm{UTS}} & =354.67+95.88 \times 10^{-3}(\mathrm{~N}) \\
& +45.53 \times 10^{-2}(\mathrm{~F})+2.02(\mathrm{r} \%) \\
& +18.64 \times 10^{-4}(\mathrm{~N} \times \mathrm{F})-50.68 \times 10^{-4}(\mathrm{~N} \times \mathrm{r} \%) \\
& -67.11 \times 10^{-3}(\mathrm{~F} \times \mathrm{r} \%)-1.28 \times 10^{-4}\left(\mathrm{~N}^{2}\right)
\end{aligned}
$$

Figure 5 shows the main and interaction plots for the mean (UTS). We noticed the following points:

- According to the main effect plot, maximum (UTS) is met when factors $\mathrm{N}, \mathrm{F}$ and $\mathrm{r} \%$ are set low, middle and low, respectively.

- When considering the $\mathrm{N} \times \mathrm{F}$ interaction plot, maximum (UTS) is achieved when $\mathrm{F}$ and $\mathrm{N}$ are set low.

- The $\mathrm{F} \times \mathrm{r} \%$ interaction plot indicates that maximum (UTS) is met when $\mathrm{F}$ is set middle and $\mathrm{r} \%$ low.

- And, finally, for the $\mathrm{N} \times \mathrm{r} \%$ interaction plot, maximum (UTS) is attained when $\mathrm{N}$ and $\mathrm{r} \%$ are set low. Accordingly, the best setting which maximizes (UTS) is when $\mathrm{N}$ and $\mathrm{r} \%$ are set low and $\mathrm{F}$ being set middle or low. The inspection of the surface contour plot shown in Figure 6 indicates that maximum (UTS) is about 283 

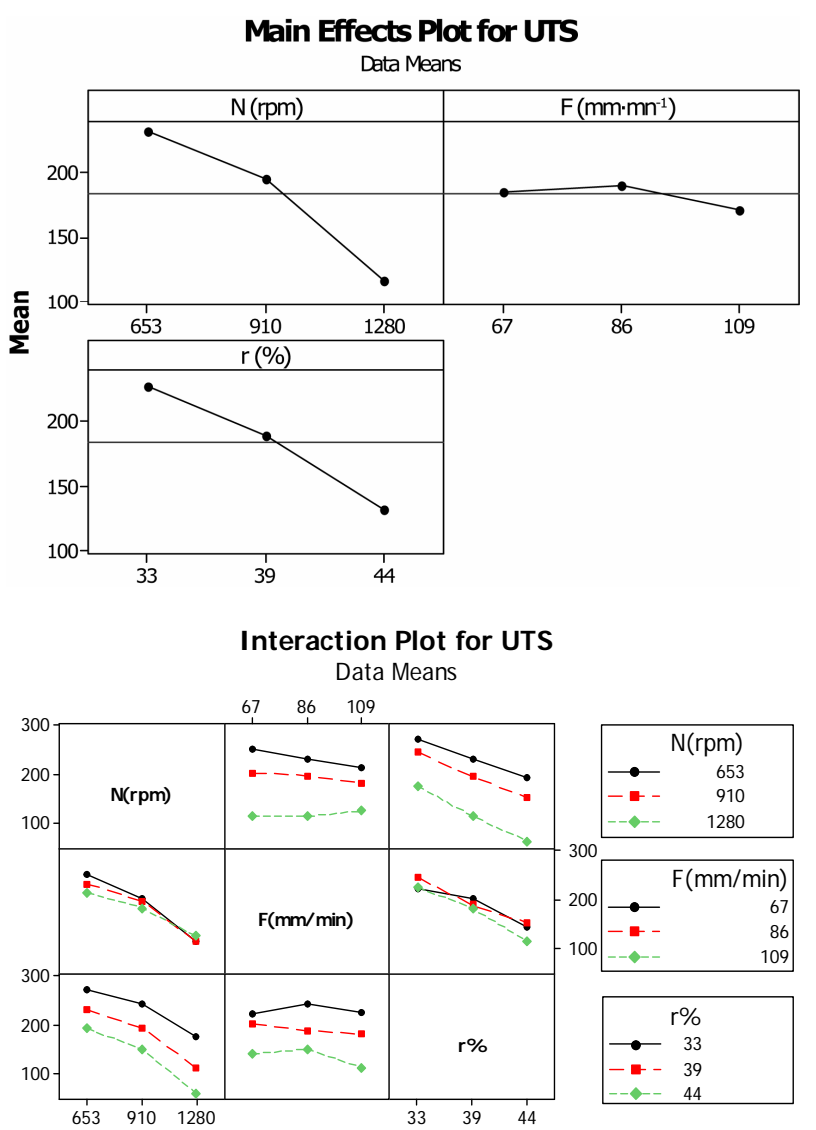

Figure 5. Main effects and interaction plots of response (UTS).

\section{Contour Plots of UTS(MPa)}
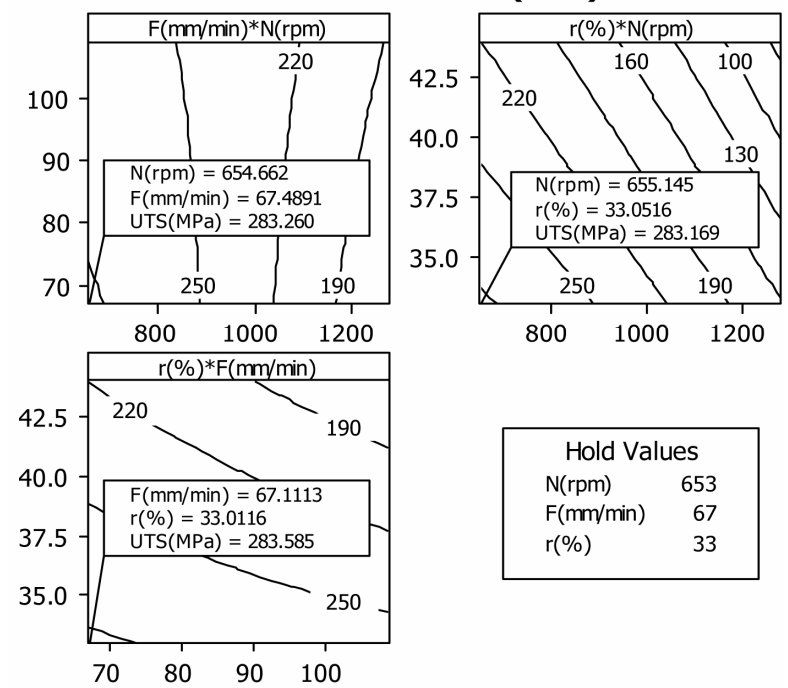

Figure 6. Surface contour plot of the process response (UTS).

$\mathrm{MPa}$ for all combination of factors spaces ( $\mathrm{N}$ versus $\mathrm{r} \%$, $\mathrm{N}$ versus $\mathrm{F}$ and $\mathrm{F}$ versus $\mathrm{r} \%$ ) given the extra factor maintained low.

\subsection{Empirical Model for the Yield Stress (YS)}

Likewise the foregoing, we seek to fit a full quadratic model to describe variation in the (YS) dataset. Allowing for a threshold of $95 \%$ C.I., the candidate/potential regression model(s) should satisfy the best trade-off among the model statistics, i.e., the LoF, $\mathrm{R}^{2}, \mathrm{R}^{2}$-pred, $\mathrm{R}^{2}$-adj and $\mathrm{S}$. In Table 5(b), it is indicated that the full quadratic model $\left(\mathrm{N}, \mathrm{F}, \mathrm{r} \%, \mathrm{~N} \times \mathrm{F}, \mathrm{F} \times \mathrm{r} \%, \mathrm{~N} \times \mathrm{r} \%, \mathrm{~N}^{2}, \mathrm{~F}^{2}, \mathrm{r} \%{ }^{2}\right)$ is not considered fit (LoF $0.03<0.05$ ). For the residuals, the 4-plots graph do not question the model adequacy as it is shown in Figure 7. The ANOVA given in Appendix $\mathrm{B}$, pointed out the regression $\mathrm{p}$-values of the interactions $(p=0.192)$ and the squared terms $(p=0.03<0.05)$ suggesting presence of curvature in the response surface which mainly originates from the squared terms. When considering the factors effects, the ANOVA shows that only $\mathrm{N}(\mathrm{p}=0.000), \mathrm{r} \%(\mathrm{p}=0.000)$ and roughly $\mathrm{r}^{2}(\mathrm{p}=$ 0.094 ) are found statistically significant at $5 \%$ of Type I error.

A reduced model of (YS) is then obtained by getting rid of insignificant terms (main + interactions). Following is the regression equation as expressed in active coding.

$$
\begin{aligned}
\overline{\mathrm{YS}}= & 342.98-14.69 \times 10^{-3}(\mathrm{~N}) \\
& -13.05(\mathrm{r} \%)+14.77 \times 10^{-2}\left(\mathrm{r} \%^{2}\right)
\end{aligned}
$$

From Equation (2), it is shown that the (YS) response is independent of factor $(F)$. Yet, it is advised to keep it at low level as the main effects plot suggests (Figure 8). Also, owing to the negative coefficient of terms $\mathrm{N}$ and $\mathrm{r} \%$ in Equation (2), lower are $\mathrm{N}$ and $\mathrm{r} \%$ higher is the process response (YS). This is further corroborated by the main effect plot shown in Figure 8. The surface contour plot which is displayed in Figure 8 shows that maximum yield stress (YS) is met when both the rotation speed $(\mathrm{N})$ and tool diameters ratio $(\mathrm{r} \%)$ are set low and the extra factor $\mathrm{F}$ being maintained low. Graphically, maximum yield stress is obtained at about $63.5 \mathrm{MPa}$.

\section{Discussion: Sensitivity Analysis}

So far, we have studied the ANOVA(s) pertaining to the (UTS) and (YS) responses. These have concerned the variability propagation through the RSM models (Equations (1) and (2)) and resulting in a significant contribution to the overall output(s). The sensitivity analysis seeks, rather, to find out what process factors do produce larger variation in the responses whenever it is subjected to an infinitesimally variation. Given a dependent variable, $\mathrm{Y}\left(\mathrm{x}_{\mathrm{i}}\right)$, the sensitivity coefficient (SC) of $\mathrm{x}_{\mathrm{i}}$ on $\mathrm{Y}\left(\mathrm{x}_{\mathrm{i}}\right)$ is obtained by calculating the partial derivative of $\mathrm{Y}\left(\mathrm{x}_{\mathrm{i}}\right)$ with respect to the independent factor $\mathrm{x}_{\mathrm{i}}$ [27]. 


\section{Residual Plots for YS}
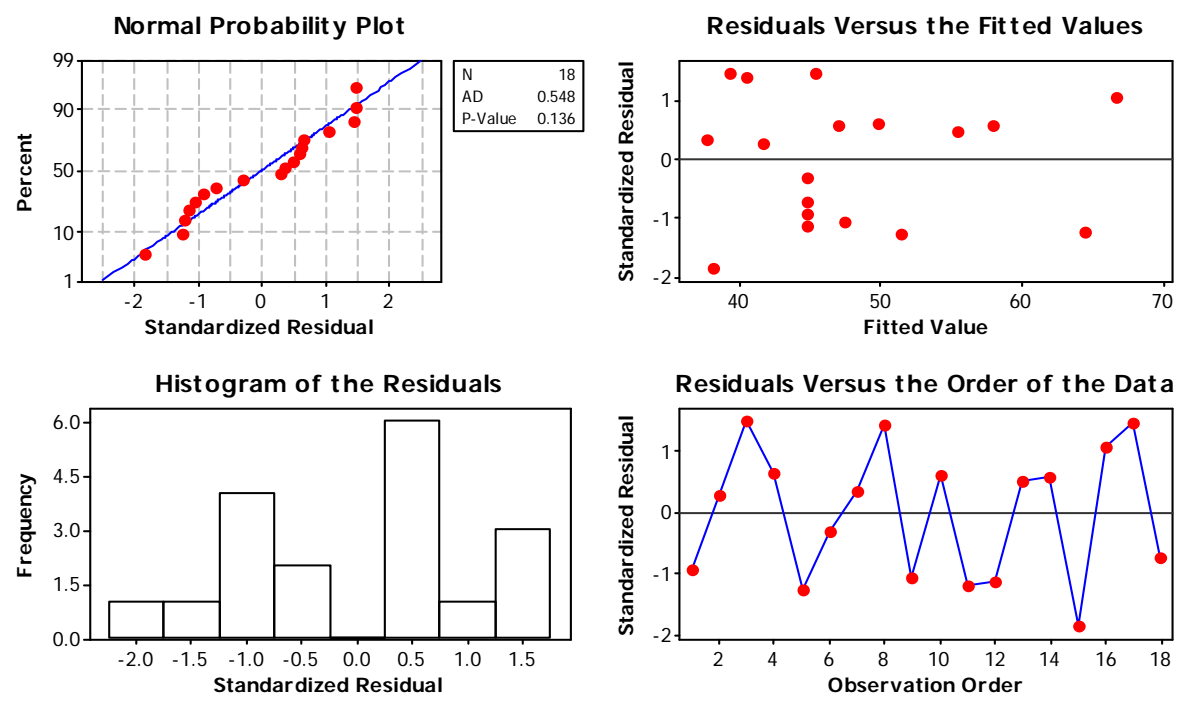

Figure 7. Four-plots for the full quadratic model of YS.

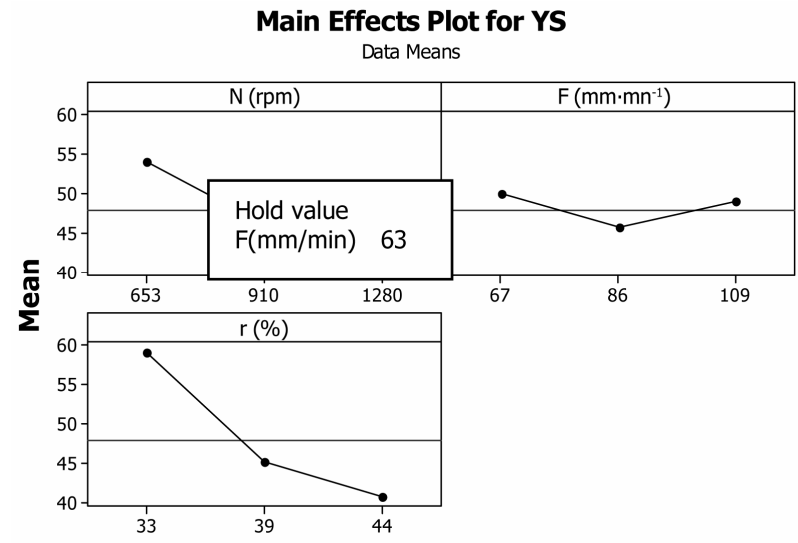

$\left(\mathrm{x}_{\mathrm{i}} / \mathrm{Y}\right)$ ratio, hence,

$$
\Phi_{n_{x i}}=S_{n}(Y) / x_{i}=\frac{\partial Y}{\partial x_{i}} \frac{x_{i}}{Y}
$$

\subsection{Sensitivity Analysis of the Ultimate Tensile Stress (UTS)}

The calculation of the partial derivatives (direct method) of the regression model of (UTS) with respect to factors N, $\mathrm{F}$, and $\mathrm{r} \%$ is calculated to ascertain the normalized coeficients $\Phi_{\mathrm{i}=\mathrm{N}, \mathrm{F}, \mathrm{r} \%}$. These are given below:

$$
\begin{gathered}
10^{4} \Phi_{\mathrm{N}}=[958.8-2.6(\mathrm{~N})+18.6(\mathrm{~F})-50.7(\mathrm{r} \%)] \frac{\mathrm{N}}{\mathrm{UTS}} \\
10^{4} \Phi_{\mathrm{F}}=[4553.0+18.6(\mathrm{~N})-671.1(\mathrm{r} \%)] \frac{\mathrm{F}}{\mathrm{UTS}} \\
10^{4} \Phi_{\mathrm{r} \%}=[20177-50.7(\mathrm{~N})-671.1(\mathrm{~F})] \frac{\mathrm{r} \%}{\mathrm{UTS}}
\end{gathered}
$$

In Table 6, the $\Phi_{\mathrm{N}, \mathrm{F}, \mathrm{r} \%}$, are calculated by averaging over all combinations of factors levels. From the histograms shown in Figure 9, we highlight the following points.

- In average, the tool traverse feed factor $(\mathrm{F})$ is insensitive to the process response (UTS) despite of the N, F and $\mathrm{r} \%$ setting levels.

Figure 8. Response (YS): Main effects plot and Surface contour plot.

$$
\Phi_{\mathrm{x}_{\mathrm{i}}}=\mathrm{SC}(\mathrm{Y})_{\mathrm{x}_{\mathrm{i}}}=\frac{\partial \mathrm{Y}}{\partial \mathrm{x}_{\mathrm{i}}}
$$

Usually, the normalized sensitivity coefficient $\left(\mathrm{SC}_{\mathrm{n}}\right)$ is utilized to avoid the unit effect by introducing the

- Allowing for the factors $\mathrm{N}$ and $\mathrm{r} \%$, the histograms in Figures 9(a)-(c), indicate that, in average, the tool diameters ratio $(\mathrm{r} \%)$ is the major sensitive factor on (UTS). It is seconded by the tool rotation speed (N). The maximum sensitivity of $\mathrm{r} \%$ on (UTS) is met when $(\mathrm{N})$ is set high $\left(\Phi_{\mathrm{r} \%}=-4.31\right)$. The sensitivities of $\mathrm{N}$ and $\mathrm{r} \%$ on (UTS) do not vary with the traverse 


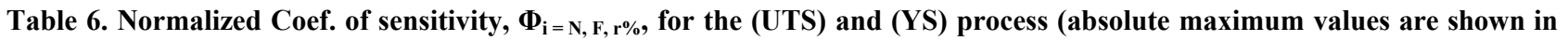
bolt).

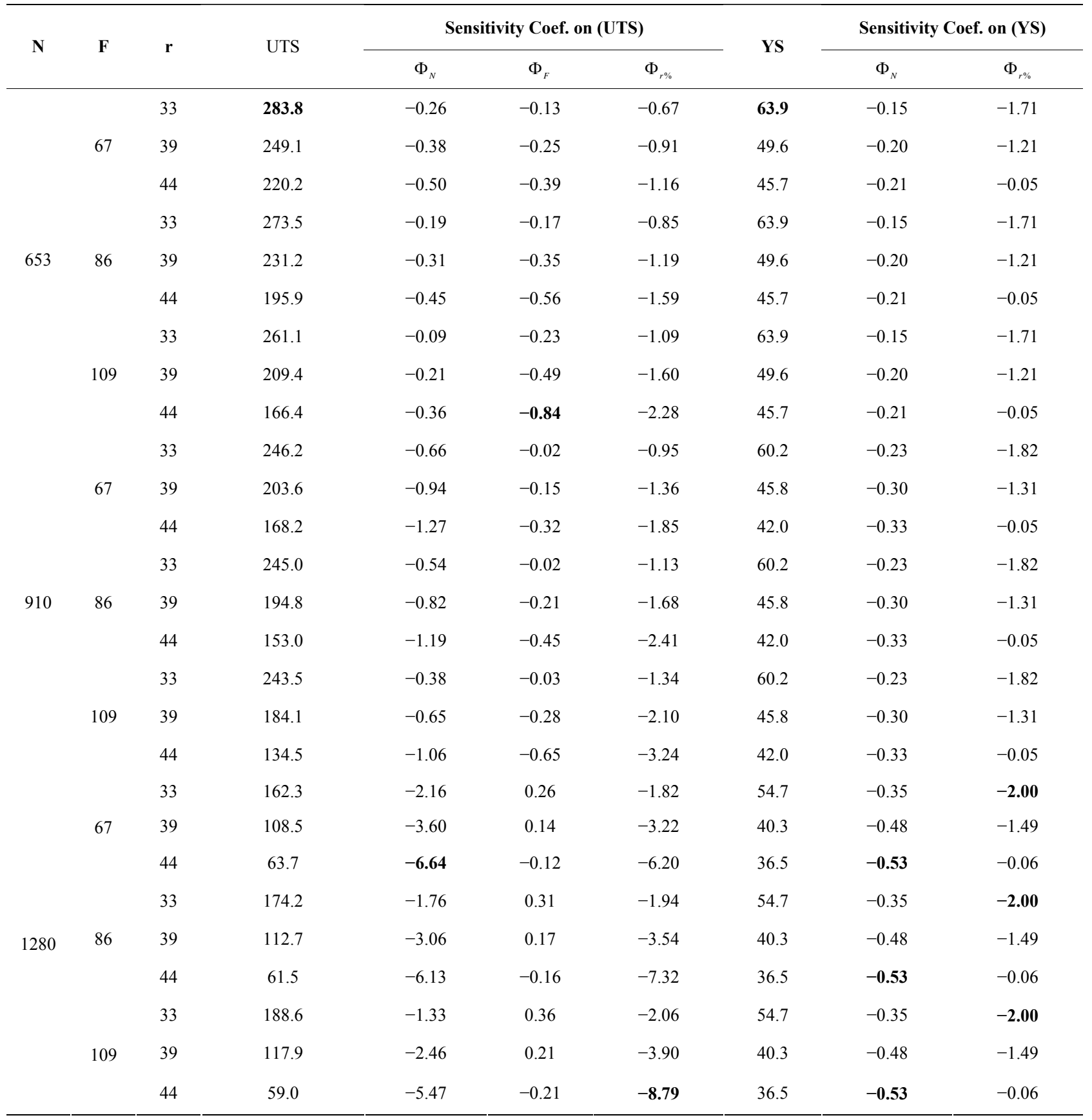

feed (F) as it is pointed out in Figure 9(b). The histogram of Figure 9(a) shows that the maximum sensitivity of $\mathrm{N}$ on (UTS) occurs at the vicinity of $\mathrm{N}$ high $\left(\Phi_{\mathrm{N}}=-3.62\right)$.

- Table 6 indicates that local maximum sensitivity of $\mathrm{N}$ $\left(\Phi_{\mathrm{N}}=-6.64\right), \mathrm{F}\left(\Phi_{\mathrm{F}}=-0.84\right)$ and $\mathrm{r} \%\left(\Phi_{\mathrm{r} \%}=-8.79\right)$ on (UTS) were found when N, F and $\mathrm{r} \%$ are set (high, low, high), (low, high, high) and (high, high, high), respectively.

\subsection{Sensitivity Analysis of the Yield Stress (YS)}

The sensitivity analysis of factors $\mathrm{N}, \mathrm{F}$ and $\mathrm{r} \%$ on (YS) is assessed using the partial derivatives (direct method) of the regression model as formulated in Equation (2). Accordingly, $\Phi_{\mathrm{i}=\mathrm{N}, \mathrm{F}, \mathrm{r} \%}$ are given below:

$$
\Phi_{\mathrm{N}}=\left[-14.7 \times 10^{-3}\right] \frac{\mathrm{N}}{\mathrm{YS}}
$$

$$
\Phi_{\mathrm{F}}=0
$$




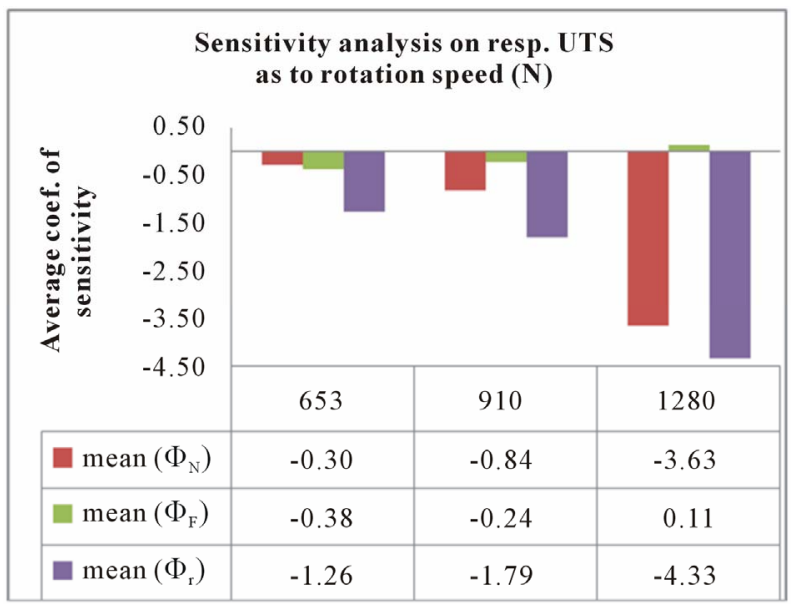

(a)

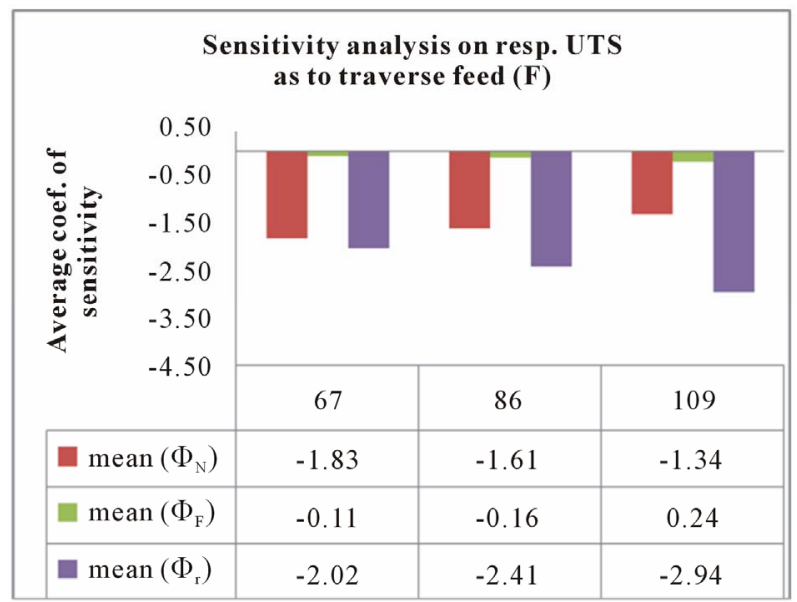

(b)

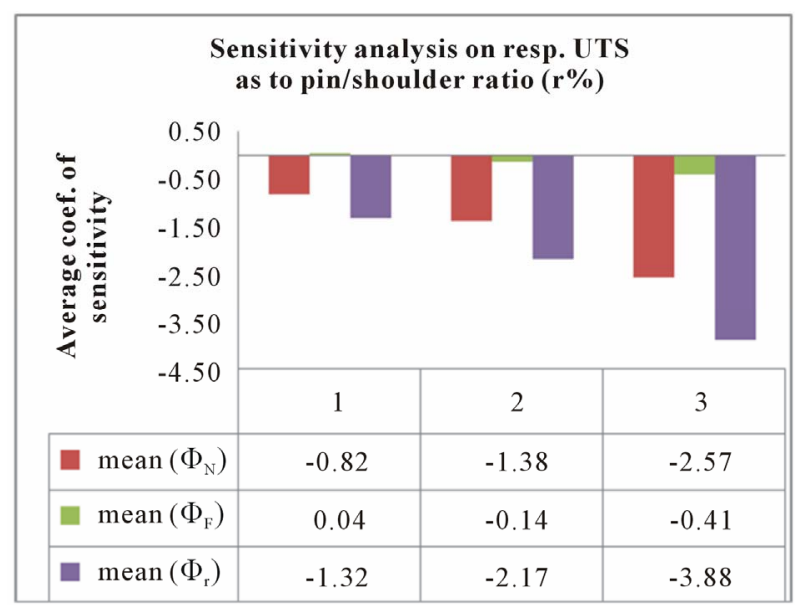

(c)

Figure 9. Sensitivity analysis for the process response (UTS): (a) when varying the tool rotation speed $(\mathrm{N})$, (b) when varying the traverse feed $(F)$, and (c) when varying the tool diameters ratio ( $(\mathrm{\%} \%)$.

$$
\Phi_{\mathrm{r} \%}=[-13.0+0.3(r \%)] \frac{\mathrm{r} \%}{\mathrm{YS}}
$$

- The histogram shown in Figure 10(a) points out the sensitivity of $\mathrm{N}$ on (YS) is almost stationary when varying $\mathrm{N}$.

- Allowing for the factors $r \%$, the histograms of Figures 10(a) and 10(b) demonstrate that in average the tool diameters ratio $(\mathrm{r} \%)$ is unique sensitive factor on (YS).

- According to Table 6, the local maximum sensitivity of $\mathrm{N}\left(\Phi_{\mathrm{N}}=-0.53\right)$, and $\mathrm{r} \%\left(\Phi_{\mathrm{r} \%}=-2.0\right)$ on (YS) were observed when $\mathrm{N}, \mathrm{F}$ and $\mathrm{r} \%$ are set (high, low, high), (high, middle, high) or (high, high, high) for the former (i.e., factor $\mathrm{N}$ ) and (high, low, low), (high, middle, low) or (high, high, low) for the latter.

\section{Concluding Remarks}

The paper has investigated the influence of three FSW parameters on two process responses, namely, the joint Ultra Tensile Stress (UTS) and the joint Yield Stress (YS) produced in the aluminum 2017AA.

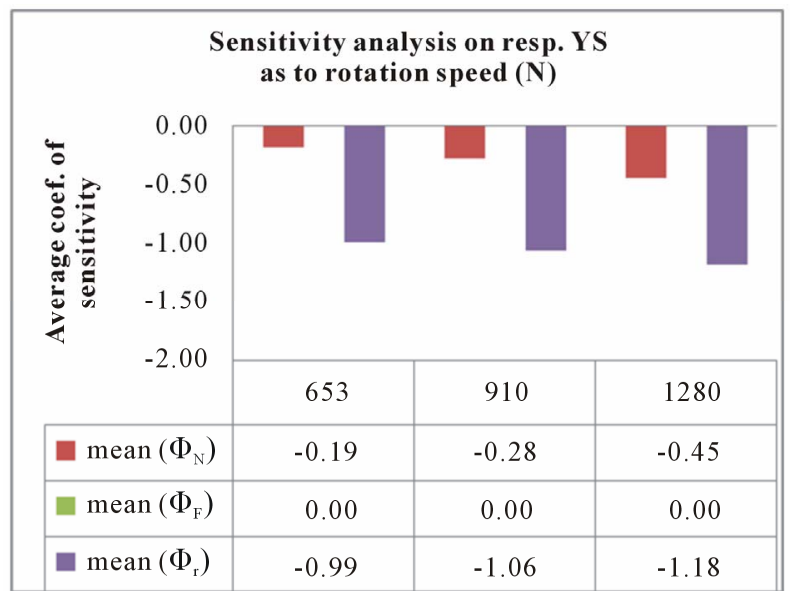

(a)

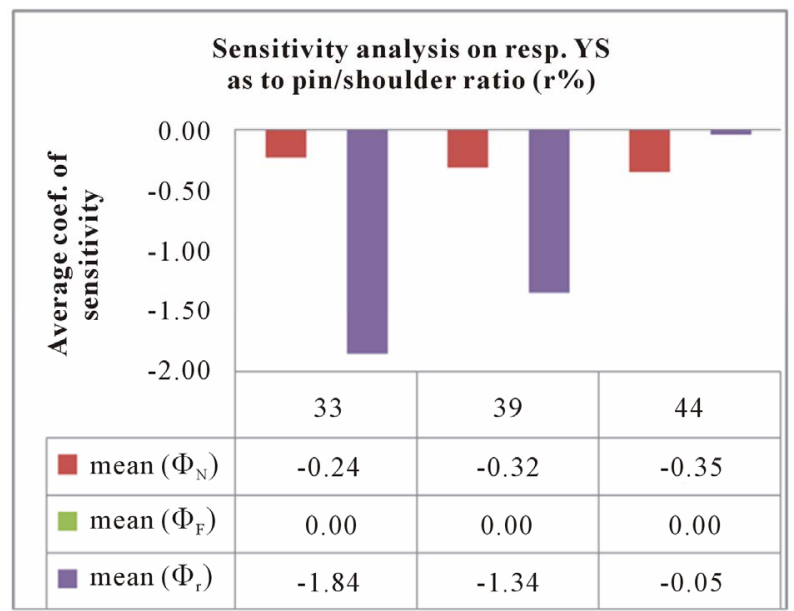

(b)

Figure 10. Sensitivity analysis for the process response (YS), (a) when varying the tool rotation speed $(N)$, and (b) when varying the tool diameters ratio $(\mathbf{r} \%)$. 
1) The predictive models of (UTS) and (YS) are found fit using quadratic RSM models;

2) The ANOVAs and summary of fit tables (Appendixes $\mathbf{A}$ and $\mathbf{B}$ ) have uncovered the traverse feed (F) was found irrelevant to the variation in (UTS) and (YS) because of the very small coefficient put in play in the regression Equations (1) and (2).

3) In average, the sensitivity analysis of factors N, F and $\mathrm{r} \%$ on the responses (UTS) and (YS) has emphasized the influence of the tool diameters ratio factor $(\mathrm{r} \%)$. The sensitivity of the tool rotation speed (N) on (UTS) came seconded in terms of prevalence. Likewise, the FSW process sensitivity was robust vis-à-vis the tool traverse feed factor (F).

The paper findings have shown that the tool geometry can be highly effective at the variation of the (UTS) and (YS) and can have significantly beneficial impacts on the quality engineering of the friction stir welded 2017AA. Besides, a shift of the factors variation space should be thought of so that a trade-off between joint macroscopic observations and the optimal parameters for FSW could be reached.

\section{REFERENCES}

[1] W. M. Thomas, E. D. Nicholas, J. C. Needham, M. G. Murch, S. P. Temple and C. J. Dawes, "Improvements Relating to Friction Welding," GB Patent No. 9125978. 8, 1991.

[2] R. Rai, H. K. D. H. Bhadeshia and T. Debroy, "Friction Stir Welding Tools, Science and Technology of Welding and Joining," Science and Technology of Welding \& Joining, Vol. 16, No. 4, 2011, pp. 325-342. doi:10.1179/1362171811Y.0000000023

[3] T. P. Chen and W. B. Lin, "Optimal FSW Process Parameters for Interface and Welded Zone Toughness of Dissimilar Aluminum-Steel Joint," Science and Technology of Welding \& Joining, Vol. 15, No. 4, 2010, pp. 279285. doi:10.1179/136217109X12518083193711

[4] G. H. Payganeh, N. B. Mostafa Arab, Y. Dadgar Asl, F. A. Ghasemi and M. S. Boroujeni, "Effects of Friction Stir Welding Process Parameters on Appearance and Strength of Polypropylene Composite Welds," International Journal of Physical Sciences, Vol. 6, No. 19, 2011, pp. 45954601 .

[5] R. Nandan, T. Debroy and H. K. D. H. Bhadeshia, "Recent Advances in Friction Stir Welding-Process, Weldment Structure and Properties," Progress in Materials Science, Vol. 53, No. 6, 2008, pp. 980-1023. doi:10.1016/i.pmatsci.2008.05.001

[6] M. Peel, A. Steuwer, M. Preuss and P. J. Withers, "Microstructure, Mechanical Properties and Residual Stresses as a Function of Welding Speed in Aluminum AA5083 Friction Stir Welds," Acta Materialia, Vol. 51, No. 16, 2003, pp. 4791-4801.

[7] K. Elangovan and V. Balasubramanian, "Influences of Tool Pin Profile and Tool Shoulder Diameter on the For- mation of Friction Stir Processing Zone in AA6061 Aluminum Alloy," Materials \& Design, Vol. 29, No. 2, 2008, pp. 362-373. doi:10.1016/i.matdes.2007.01.030

[8] A. Razal, K. Manisekar and V. Balasubramanian, "Influences of Welding Speed on Tensile Properties of Friction Stir Welded AZ61A Magnesium Alloy," Journal of Materials Engineering and Performance, Vol. 21, No. 2, 2012, pp. 257-265. doi:10.1007/s11665-011-9889-0

[9] S. Lim, S. Kim, C. Lee and S. Kim, "Tensile Behavior of Friction-Stir-Welded A16061-T651," Metallurgical and Materials Transactions A, Vol. 35A, No. 9, 2004, pp. 2829-2835. doi:10.1007/s11661-004-0230-5

[10] H. Okuyucu, A. Kurt and E. Arcaklioglu, "Artificial Neural Network Application to the Friction Stir Welding of Aluminum Plates," Materials \& Design, Vol. 28, No. 1, 2007, 78-84. doi:10.1016/j.matdes.2005.06.003

[11] M. Jayaraman, R. Sivasubramanian and V. Balasubramanian, "Establishing Relationship between the Base Metal Properties and Friction Stir Welding Process Parameters of Cast Aluminum Alloys," Materials \& Design, Vol. 31, No. 3, 2010, pp. 4567-4576. doi:10.1016/j.matdes.2010.03.040

[12] K. Elangovan and V. Balasubramanian, "Influences of Pin Profile and Rotational Speed of the Tool on the Formation of Friction Stir Processing Zone in AA2219 Aluminum Alloy," Materials Science and Engineering: A, Vol. 459, No. 1-2, 2007, pp. 7-18.

[13] S. Rajakumar, C. Muralidharan and V. Balasubramanian, "Influence of Friction Stir Welding Process and Tool Parameters on Strength Properties of AA7075-T6 Aluminum Alloy Joints," Materials \& Design, Vol. 32, No. 2, 2011, pp. 535-549. doi:10.1016/i.matdes.2010.08.025

[14] K. Kumar and S. V. Kailas, "On the Role of Axial Load and the Effect of Interface Position on the Tensile Strength of a Friction Stir Welded Aluminum Alloy," Materials \& Design, Vol. 29, No. 4, 2008, pp. 791-797. doi:10.1016/j.matdes.2007.01.012

[15] C. Bitondo, U. Prisco, A. Squilace, P. Buonadonna and G. Dionoro, "Friction-Stir Welding of AA 2198 Butt Joints: Mechanical Characterization of the Process and of the Welds through DOE Analysis," The International Journal of Advanced Manufacturing Technology, Vol. 53, No. 5-8, 2011, pp. 505-516. doi:10.1007/s00170-010-2879-9

[16] H. K. Mohanty, D. Venkateswarlu, M. Mahapatra and N. R. Kumar, "Modeling the Effects of Tool Probe Geometries and Process Parameters on Friction Stirred Aluminium Welds," Journal of Mechanical Engineering and Automation, Vol. 2, No. 4, 2012, pp. 74-79. doi:10.5923/j.jmea.20120204.04

[17] S. Rajakumar, C. Muralidharan and V. Balasubramanian, "Establishing Empirical Relationships to Predict Grain Size and Tensile Strength of Friction Stir Welded AA 6061-T6 Aluminum Alloy Joints," Transactions of Nonferrous Metals Society of China, Vol. 20, No. 10, 2010, pp. 1863-1872. doi:10.1016/S1003-6326(09)60387-3

[18] S. Rajakumar and V. Balasubramanian, "Multi-Response Optimization of Friction-Stir-Welded AA1100 Aluminum Alloy Joints," Journal of Materials Engineering and Per- 
formance, Vol. 21, No. 6, 2012, pp. 809-822. doi:10.1007/s11665-011-9979-Z

[19] R. Palanivel, P. K. Mathews and N. Murugan, "Development of Mathematical Model to Predict the Mechanical Properties of Friction Stir Welded AA6351 Aluminum Alloy," Journal of Engineering Science and Technology Review, Vol. 4, No. 1, 2011, pp. 25-31.

[20] A. K. Lakshminarayanan and V. Balasubranian, "Process Parameters Optimization for Friction Stir Welding of RDE-40 Aluminum Alloy Using Taguchi Technique," Transactions of Nonferrous Metals Society of China, Vol. 18 , No. 3, 2008, pp. 548-554. doi:10.1016/S1003-6326(08)60096-5

[21] A. S. Vagh and S. N. Pandya, "Influence of Process Parameters on the Mechanical Properties of Friction Stir Welded AA2014-T6 Alloy Using Taguchi Orthogonal Array," International Journal of Engineering Sciences \& Emerging Technologies, Vol. 2, No. 1, 2012, pp. 51-58.

[22] K. Brahma Raju, N. Harsha and V. K. Viswanadha Raju, "Prediction of Tensile Strength of Friction Steer Welded Joints Using Artificial Neural Networks," International Journal of Engineering Research \& Technology, Vol. 1, No. 1, 2012, pp. 1-5.

[23] I. N. Tansel, M. Demetgul, H. Okuyucua and A. Yapici, "Optimizations of Friction Stir Welding of Aluminum
Alloy by Using Genetically Optimized Neural Network," The International Journal of Advanced Manufacturing Technology, Vol. 48, No. 1-4, 2010, pp. 95-101. doi:10.1007/s00170-009-2266-6

[24] H. J. Liu, H. Fujii, M. Maedaa and K. Nogi, “Tensile Properties and Fracture Locations of Friction-Stir-Welded Joints of 2017-T351 Aluminum Alloy," Journal of Materials Processing Technology, Vol. 142, No. 3, 2003, pp. 692-699. doi:10.1016/S0924-0136(03)00806-9

[25] A. Mirjalil, H. J. Aval, S. Serajzadeh and A. H. Kokabi, "Microstructural Evolution and Mechanical Properties of FSWed 2017 AA with Different Initial Microstructures," Proceedings of the Institution of Mechanical Engineers. Part L: Journal of Materials: Design and Applications, 2013. doi: $10.1177 / 1464420713476400$

[26] A. Trabelsi, M. A. Rezgui and S. Bezzina, "Assessment of the Tensile Elongation ( $\mathrm{e} \%$ ) and Hardening Capacity (Hc) of Joints Produced in Friction Stir Welded 2017 AA (Enaw-AlCu4MgSi) Plates," International Journal of Engineering and Advanced Technology, Vol. 2, No. 4, 2013.

[27] D. M. Hamby, "A Review of Techniques for Parameter Sensitivity Analysis of Environmental Models," Environmental Monitoring and Assessment, Vol. 32, No. 2, 1994, pp. 135-154. doi:10.1007/BF00547132 
Appendix A. Regression Models and ANOVA results for the UTS response using coded units.

\begin{tabular}{|c|c|c|c|c|c|c|c|c|}
\hline \multirow{2}{*}{$\begin{array}{c}\text { Models } \\
\text { Term }\end{array}$} & \multicolumn{4}{|c|}{ Full quadratic model } & \multicolumn{4}{|c|}{ Reduced model } \\
\hline & Coef & SE Coef & $\mathbf{T}$ & P-value & Coef & SE Coef & $\mathbf{T}$ & P-value \\
\hline Constant & 188.54 & 2.57 & 73.39 & 0.000 & 188.02 & 2.13 & 88.46 & 0.000 \\
\hline $\mathrm{N} /\left(\mathrm{r} \cdot \mathrm{min}^{-1}\right)$ & -57.31 & 1.99 & -28.76 & 0.000 & -57.31 & 1.81 & -31.67 & 0.000 \\
\hline $\mathrm{F} /\left(\mathrm{mm} \cdot \mathrm{min}^{-1}\right)$ & -6.82 & 1.99 & -3.42 & 0.009 & -6.86 & 1.81 & -3.80 & 0.004 \\
\hline $\mathrm{r} /(\%)$ & -48.36 & 1.99 & -24.26 & 0.000 & -48.33 & 1.81 & -26.73 & 0.000 \\
\hline $\mathrm{N}^{*} \mathrm{~N}$ & -11.38 & 3.97 & -2.86 & 0.021 & -12.59 & 2.83 & -4.45 & 0.001 \\
\hline $\mathrm{F}^{*} \mathrm{~F}$ & -1.28 & 3.87 & -0.33 & 0.750 & & & - & - \\
\hline $\mathrm{r} \% * \mathrm{r} \%$ & -0.88 & 3.86 & -0.23 & 0.825 & & & - & - \\
\hline $\mathrm{N} * \mathrm{~F}$ & 12.27 & 2.22 & 5.53 & 0.001 & 12.27 & 2.01 & 6.10 & 0.000 \\
\hline $\mathrm{N}^{*} \mathrm{r} \%$ & -8.74 & 2.22 & -3.94 & 0.004 & -8.74 & 2.01 & -4.34 & 0.001 \\
\hline $\mathrm{F} * \mathrm{r} \%$ & -7.75 & 2.22 & -3.49 & 0.008 & -7.75 & 2.02 & -3.84 & 0.003 \\
\hline ANOVA & \multicolumn{4}{|c|}{ Full Quadratic model } & \multicolumn{4}{|c|}{ Reduced model } \\
\hline Source & DF & Adj SS & $\mathbf{F}$ & P-value & DF & Adj SS & $\mathbf{F}$ & P-value \\
\hline Regression & 9 & 61054.8 & 171.02 & 0.000 & 7 & 61045.1 & 266.64 & 0.000 \\
\hline Linear & 3 & 56659.2 & 476.12 & 0.000 & 3 & 56683.9 & 577.70 & 0.000 \\
\hline Square & 3 & 658.2 & 5.53 & 0.024 & 1 & 648.5 & 19.83 & 0.001 \\
\hline Interaction & 3 & 2324.3 & 19.53 & 0.000 & 3 & 2325.0 & 23.70 & 0.000 \\
\hline Residual Error & 8 & 317.3 & & & 10 & 327.1 & & \\
\hline Lack-of-Fit & 5 & 95.1 & 0.26 & 0.911 & 7 & 104.9 & 0.20 & 0.962 \\
\hline Pure Error & 3 & 222.2 & & & 3 & 222.2 & & \\
\hline Total & 17 & 61372.2 & & & 17 & 61372.2 & & \\
\hline \multirow{4}{*}{$\begin{array}{c}\text { Parameters } \\
\text { Estimate }\end{array}$} & $\mathbf{S}$ & PRESS & & LoF & $\mathbf{S}$ & \multicolumn{2}{|l|}{ PRESS } & LoF \\
\hline & 6.298 & 2381 & & 0.911 & 5.719 & \multicolumn{2}{|l|}{2026} & 0.962 \\
\hline & R-Sq & R-Sq (Pred) & & R-Sq (adj) & R-Sq & \multicolumn{2}{|l|}{ R-Sq (Pred) } & R-Sq (adj) \\
\hline & $99.5 \%$ & $96.1 \%$ & & $98.9 \%$ & $99.5 \%$ & \multicolumn{2}{|l|}{$96.7 \%$} & $99.1 \%$ \\
\hline
\end{tabular}


Appendix B. Regression Models and ANOVA results for the YS response using coded units.

\begin{tabular}{|c|c|c|c|c|c|c|c|c|}
\hline \multirow{2}{*}{$\begin{array}{c}\text { Models } \\
\text { Term }\end{array}$} & \multicolumn{4}{|c|}{ Full Quadratic model } & \multicolumn{4}{|c|}{ Reduced model } \\
\hline & Coef & SE Coef & $\mathbf{T}$ & P-value & Coef & SE Coef & $\mathbf{T}$ & P-value \\
\hline Constant & 44.61 & 1.06 & 42.04 & 0.000 & 45.36 & 1.02 & 44.67 & 0.000 \\
\hline $\mathrm{N} /\left(\mathrm{r} \cdot \min ^{-1}\right)$ & -4.70 & 0.82 & -5.70 & 0.000 & -4.61 & 0.89 & -5.19 & 0.000 \\
\hline $\mathrm{F} /\left(\mathrm{mm} \cdot \mathrm{min}^{-1}\right)$ & -0.43 & 0.82 & -0.52 & 0.618 & & & - & - \\
\hline $\mathrm{r} /(\%)$ & -9.17 & 0.82 & -11.13 & 0.000 & -9.20 & 0.89 & -10.32 & 0.000 \\
\hline $\mathrm{N}^{*} \mathrm{~N}$ & 1.25 & 1.64 & 0.76 & 0.468 & & & - & - \\
\hline $\mathrm{F}^{*} \mathrm{~F}$ & 1.45 & 1.60 & 0.91 & 0.391 & & & - & - \\
\hline $\mathrm{r} \% * \mathrm{r} \%$ & 3.04 & 1.60 & 1.90 & 0.094 & 4.47 & 1.36 & 3.30 & 0.005 \\
\hline $\mathrm{N} * \mathrm{~F}$ & 1.56 & 0.92 & 1.71 & 0.126 & & & - & - \\
\hline $\mathrm{N} * \mathrm{r} \%$ & 1.36 & 0.92 & 1.49 & 0.176 & & & - & - \\
\hline $\mathrm{F} * \mathrm{r} \%$ & -0.87 & 0.92 & -0.95 & 0.370 & & & - & - \\
\hline ANOVA & \multicolumn{4}{|c|}{ Full Quadratic model } & \multicolumn{4}{|c|}{ Reduced model } \\
\hline Source & DF & Adj SS & $\mathbf{F}$ & P-value & DF & Adj SS & $\mathbf{F}$ & P-value \\
\hline Regression & 9 & 1220.75 & 20.04 & 0.000 & 3 & 1163.65 & 48.81 & 0.000 \\
\hline Linear & 3 & 1061.47 & 52.27 & 0.000 & 2 & 1060.72 & 66.74 & 0.000 \\
\hline Square & 3 & 101.86 & 5.02 & 0.030 & 1 & 86.64 & 10.90 & 0.005 \\
\hline Interaction & 3 & 40.75 & 2.01 & 0.192 & & & & \\
\hline Residual Error & 8 & 54.16 & & & 14 & 111.25 & & \\
\hline Lack-of-Fit & 5 & 51.97 & 14.25 & 0.027 & 5 & 33.54 & 0.78 & 0.590 \\
\hline Pure Error & 3 & 2.19 & & & 9 & 77.71 & & \\
\hline Total & 17 & 1274.9 & & & 17 & 1274.90 & & \\
\hline \multirow{4}{*}{$\begin{array}{c}\text { Parameters } \\
\text { Estimate }\end{array}$} & $\mathbf{S}$ & PRESS & & LoF & $\mathbf{S}$ & \multicolumn{2}{|l|}{ PRESS } & LoF \\
\hline & 2.602 & 438 & & 0.027 & 2.819 & \multicolumn{2}{|l|}{192} & 0.59 \\
\hline & R-Sq & R-Sq (Pred) & & R-Sq (adj) & R-Sq & \multicolumn{2}{|l|}{ R-Sq (Pred) } & R-Sq (adj) \\
\hline & $95.8 \%$ & $65.6 \%$ & & $91.0 \%$ & $91.3 \%$ & \multicolumn{2}{|l|}{$85.0 \%$} & $89.4 \%$ \\
\hline
\end{tabular}

